\title{
Knowledge Translation in Heart Failure
}

Darshan H. Brahmbhatt, MA(Cantab) MPhil MRCS(Eng) MRCP(Lon); Jeremy Kobulnik, MD, FRCPC

\author{
About the Authors \\ Darshan H. Brahmbhatt is with the Division of Cardiology, Department of Medicine, University of Toronto, Canada and the National \\ Heart \& Lung Institute, Imperial College London, UK \\ Jeremy Kobulnik, MD FRCPC is with the Division of Cardiology, Department of Medicine, University of Toronto, Canada and Mount \\ Sinai Hospital and Toronto General Hospital, Toronto, Canada \\ Corresponding Author: Jeremy.Kobulnik@sinaihealthsystem.ca \\ Submitted: January 29, 2020. Accepted: February 5. Published: April 8, 2020. DOI: 10.22374/cjgim.v15iSP1.421.
}

\begin{abstract}
The treatment of heart failure has expanded over the past three decades with large numbers of new medications and healthcare innovations available for these patients. At the same time, the prevalence of heart failure continues to increase across Canada and these patients are managed by a variety of clinicians from differing backgrounds in both primary care and hospital settings. Despite national recommendations advocating uptake of these new therapies, their utilization remains limited and inconsistent across the country. This review discusses the importance of knowledge translation in heart failure and examines the barriers to implementation of new therapies and models of care, providing a range of solutions to facilitate the delivery of guidelinedirected care for heart failure patients.
\end{abstract}

\section{Resume}

Le traitement de l'insuffisance cardiaque s'est développé au cours des trois dernières décennies grâce à un grand nombre de nouveaux médicaments et d'innovations en matière de soins de santé disponibles pour ces patients. Dans le même temps, la prévalence de l'insuffisance cardiaque continue d'augmenter dans tout le Canada et ces patients sont pris en charge par divers cliniciens d'horizons différents, tant dans le cadre des soins primaires que dans les hôpitaux. Malgré les recommandations nationales préconisant l'adoption de ces nouvelles thérapies, leur utilisation reste limitée et inégale dans tout le pays. Cette étude traite de l'importance de l'application des connaissances en matière d'insuffisance cardiaque et examine les obstacles à la mise en œuvre des nouvelles thérapies et des nouveaux modèles de soins, en proposant une série de solutions pour faciliter la prestation de soins guidés pour les patients souffrant d'insuffisance cardiaque.

Heart failure (HF) management has been revolutionized over the past three decades and now includes several classes of drugs that inhibit the various pathological neuro-hormonal pathways, ${ }^{1}$ as well as non-pharmacological interventions such as cardiac resynchronisation therapy $(\mathrm{CRT}),{ }^{2}$ implantable cardioverter defibrillators (ICD), ${ }^{3,4}$ cardiac transplantation, and mechanical circulatory support. In Canada alone, the age-standardised allcause mortality rate in HF patients has decreased from 78.4 per
1,000 in $2000-01$, to 57.8 per 1,000 in $2012-13 .{ }^{5}$ Improvements in treatment require implementation into everyday practice and integration into the local context of healthcare. This process of knowledge translation is critical to ensuring successful uptake of new discoveries that will reduce the morbidity, mortality and cost of healthcare associated with HF. This review focuses on strategies for successful knowledge translation to improve the care pathway of HF patients while highlighting current challenges. 


\section{Clinical Vignette (Part 1)}

Jennifer, a 74-year-old female living in a small town in rural Ontario, presented to her family doctor with insidious exertional dyspnoea for three months, with reduced exercise capacity and poor sleep. She had been previously diagnosed with hypertension that was well controlled on amlodipine $5 \mathrm{mg}$ but had no other comorbidities. She previously smoked, but stopped 40 years ago, and rarely drinks alcohol. She has noticed that she cannot walk as far as she was able to last summer, being limited by breathlessness. She denies any chest pain. She has noticed a cough over the last couple of weeks.

Examination reveals a heart rate of $110 /$ minute, respiratory rate of 20/minute and arterial blood pressure of $98 / 60 \mathrm{mmHg}$, with normal heart sounds, no murmurs and fine inspiratory crepitations at the lung bases. The jugular venous pressure is not easily seen and there is bilateral ankle swelling which the patient reports as being long-standing.

The clinical suspicion is of congestive heart failure, with a differential diagnosis of possible lung pathology (emphysema or pulmonary neoplasm).

\section{Making a Diagnosis of Heart Failure}

Given the broad range of possible presenting symptoms, it can be a challenge to diagnose HF. Many symptoms are not specific to HF and there is often an overlap with other cardio-pulmonary pathologies. In this patient, there is a history compatible with HF, although the symptoms could be compatible with hypertensive heart disease or coronary artery disease, and respiratory diagnoses are also possible. Guidelines direct that possible HF diagnoses should be investigated with echocardiography, and possibly with biomarkers such as B-type natriuretic peptide (BNP) or N-terminal-pro-BNP. ${ }^{6}$

\section{Access to Investigations}

The diagnostic process proves difficult on a number of fronts. Firstly, despite evidence of benefit in making the diagnosis of HF using biomarkers, they are not widely available across Canada. Some provinces, such as British Columbia, have had access to BNP testing since 2012; nevertheless, a large number of barriers exist in requesting the test in appropriate populations. ${ }^{7}$ A retrospective cohort study in Alberta showed that geographic location played a large part in the ability to access biomarker testing, as did physician specialty. ${ }^{8}$ Access to echocardiography can also be a challenge; in our patient, the local hospital does offer echocardiography, but not necessarily a cardiology service. Therefore, the expertise available to primary care providers (PCPs) may vary greatly. Finally, several campaigns have tried to ensure diagnostic investigations are organised for appropriate patients, such as the Choosing Wisely campaign, ${ }^{9}$ however, these could potentially dissuade clinicians from requesting tests when appropriate. ${ }^{10}$ Natriuretic peptides can also be used for monitoring response to therapy, allowing family doctors and other nonspecialists to better track disease progression over time and be used to refer to specialists for advanced therapies. The Canadian Cardiovascular Society (CCS) guidelines provide a framework for appropriate use of biomarker testing ${ }^{6}$ (See Figure 1).

To further ensure consistency of approach, computerized clinical decision support systems and clinical care pathways can be

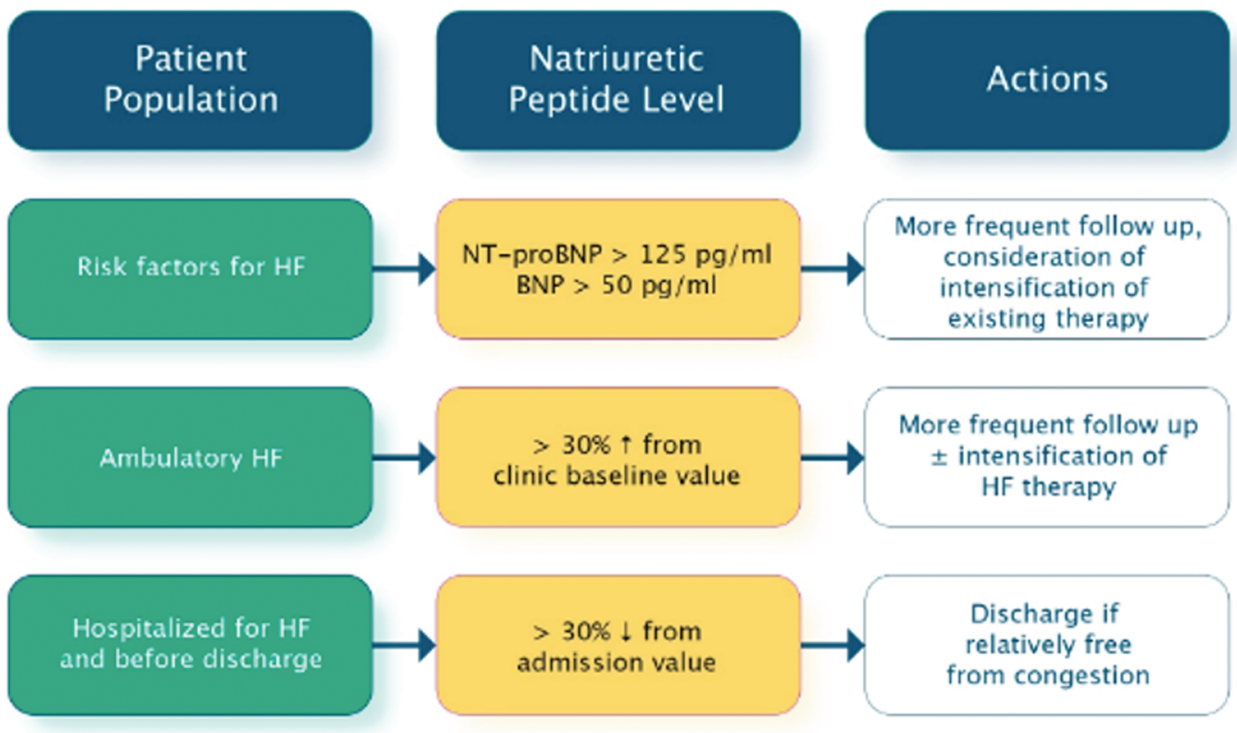

Figure 1. The Canadian Cardiovascular Society algorithm for the use of natriuretic peptides in different heart failure-related clinical scenarios. $\mathrm{BNP}=\mathrm{B}$-type natriuretic peptide; NT-proBNP = N-terminal propeptide B-type natriuretic peptide. 
a means to ensure appropriate assessment and diagnostic testing take place. ${ }^{11,12}$ These interventions are generally cost-effective and result in fewer complications. However, these approaches are not widely used in current Canadian clinical practice, but could be a way to improve adherence to guidelines.

\section{Risk Mismatch in Heart Failure}

The CCS guidelines emphasise the use of formal risk scoring. ${ }^{6}$ The risk mismatch paradox was described more than a decade ago in patients enrolled in the EFFECT registry (1999-2001). ${ }^{13}$ It demonstrated that angiotensin converting enzyme (ACE) inhibitors/angiotensin receptor blockers (ARB) and betablockers were more likely to be prescribed to lower risk patients at discharge from hospital after admission for decompensated HF. The effects of this lasted for at least a year after discharge, and even when accounting for contraindication to therapy, low-risk patients were more likely to receive ACE inhibitors or ARBs (adjusted hazard ratio [HR], 1.61; 95\% confidence interval [CI], 1.49-1.74) and beta-blockers (HR, 1.80; 95\% CI, 1.60-2.01) compared with high-risk patients (both $\mathrm{p}<0.001$ ). ${ }^{13}$ This has been corroborated by subsequent studies in different populations in the U.S. as part of the Get With The Guidelines programme that argue effective strategies need to be developed for high risk patients to receive more effective treatment. ${ }^{14}$ Formal risk stratification can ensure that patients wrongly assumed to be low risk can be managed more quickly and aggressively to improve their outcomes, as higher risk patients are often eligible for more therapeutic interventions.
The risk mismatch paradox may be partly explained by inaccuracies related to estimating risk both by physicians and patients, as well as the impracticality of using formal risk calculators. An American study examined patients' selfassessment of one-year risk alongside the same assessment by their treating physicians. ${ }^{15}$ Patients perceived their own risk of death, need for transplant or a ventricular assist device (VAD) to be $14 \%$ at one year, compared to their physicians who estimated it to be $69 \%$. During follow-up, more patients had died in the physician-assessed high-risk category than the low-risk category, but more of the low-risk patients had transplantation and VAD implantation. Importantly, neither physicians, nor patients, were accurate at predicting risk, and the disagreement between the two groups may have created barriers in discussions around the appropriateness of advanced therapies. Using formal risk scoring and patient education can more accurately inform patients about prognosis and facilitate effective application of appropriate therapy to those at highest risk along with advanced care planning.

There are several possible scoring systems, but they often require both echocardiographic and hematological parameters alongside patient symptoms and biometric data. These can be unwieldy and often require electronic software to calculate, leading to underutilization of this aspect of HF management. Furthermore, there is a concern about how relevant risk stratification is for an individual patient, in whom the outcomes are often binary, whereas they are more useful on a population level, where they can assist with provision of services. ${ }^{16,17}$

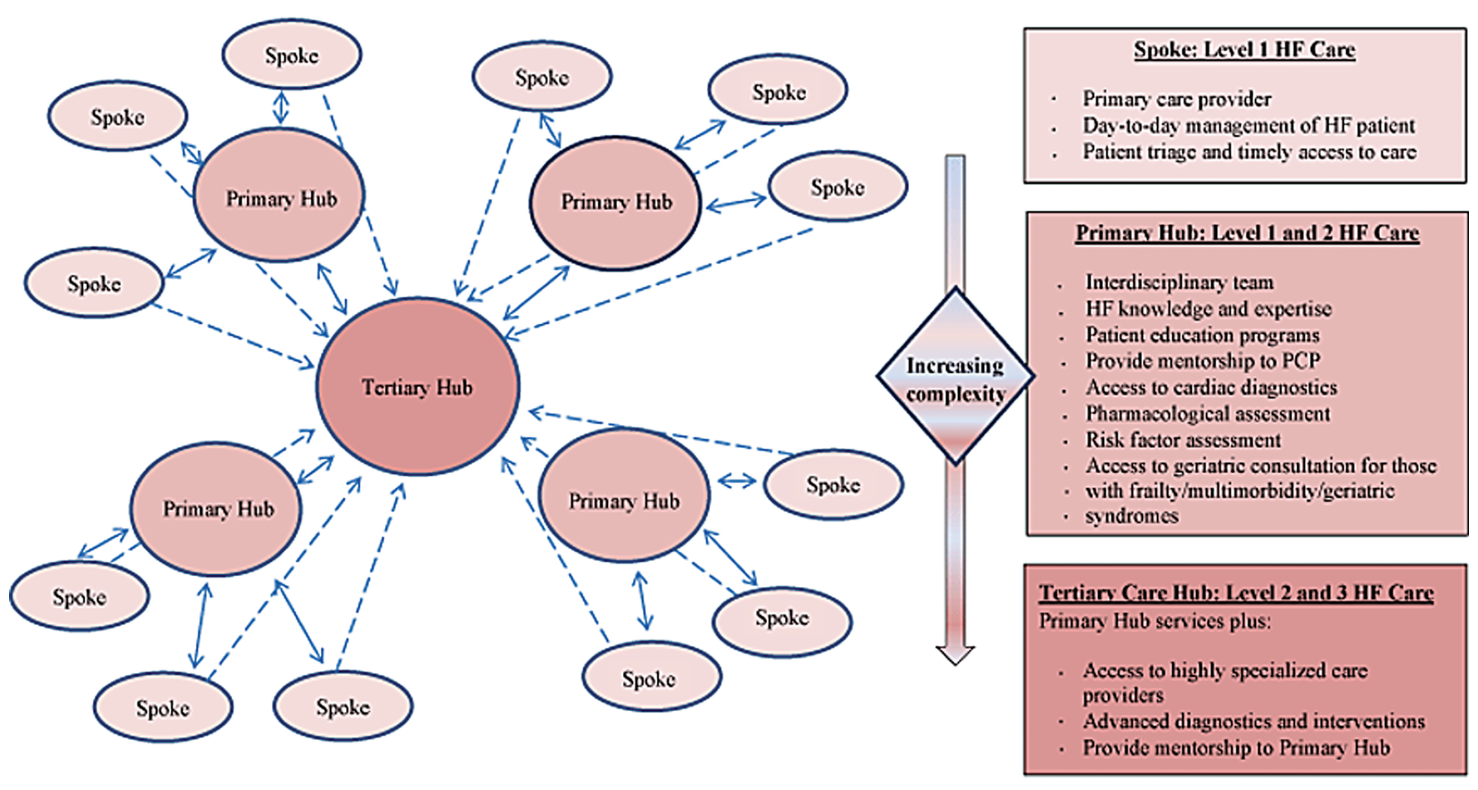

HF. Heart failure; PCP. Primary care provider

Figure 2. The hub and spoke model of care proposed by Harkness et al. ${ }^{18}$ Reproduced with permission 


\section{Organization of Heart Failure Care}

Jennifer, the patient in our vignette, lives in a rural town that has no cardiology support in its local hospital. Once the diagnosis of HF is made, it can be a challenge to access HF services. Whilst some locations may have access to cardiology services, PCPs may have trouble deciding who should be referred. Unlike surgical referrals that largely result in a discreet encounter to determine the need for intervention, HF specialist consultations often result in a management plan to be enacted locally, requiring ongoing interaction between the specialist and primary care team. The partnership between clinicians is key to successful management, with patients preferring local care that does not necessitate repeated visits to tertiary centres. Some have proposed a hub and spoke model, with delegation of responsibility and expertise down from the large tertiary centres that can focus on dealing with complex, advanced HF or symptoms refractory to usual treatment, leaving local hospital hubs able to deliver most of the hospital care to HF patients and support the PCPs in the day-to-day management of HF patients. ${ }^{18}$

PCPs often have close relationships with patients over many years, and are likely to be best placed to alter HF therapy given the need for repeated assessment of treatment efficacy and surveillance for side-effects such as hypotension and renal dysfunction. Advice and guidance from the HF specialist needs to be communicated to the local provider, and this can be a challenge depending on the clinical and geographic setting. ${ }^{19}$

\section{Role of Opinion Leaders and Continuing Education}

There is also proven benefit of outreach to community setting by "opinion leaders" who can promote and advise on implementation of best practice as guided by evidence. ${ }^{20} \mathrm{~A}$ Cochrane systematic review suggests that education meetings can improve professional practice and healthcare outcomes for patients, ${ }^{21}$ and others have identified the elements that need to be incorporated in a HF curriculum for primary care continuing medical education. ${ }^{22}$ These two mechanisms can complement alternative strategies for knowledge translation into the primary care setting, increasing the confidence of primary care specialists in providing highquality HF care close to the patient.

\section{Communication After Hospital Discharge}

A commonly reported breakdown of communication occurs at the transition from inpatient care to discharge into the community. Both patients and PCPs feel that the communication could be improved, with better guidance as to the role of the PCP, after HF hospitalisation has occurred. ${ }^{23}$ One U.S. study showed cost-savings through reduction in hospital readmissions after focussed training for hospital providers involved in discharging patients into the community. By employing a full-time HF nurse coordinator, 30-day readmissions were significantly reduced from $23.1 \%$ to $16.4 \%$ (adjusted odds ratio $[\mathrm{OR}]=0.64,95 \%$ CI: $0.42-0.97) .{ }^{24}$ Effective and timely local strategies for multidisciplinary communication seem to be key in forging stable healthcare environments for HF patients.

\section{Clinical Vignette (Part 2)}

Jennifer was commenced on oral diuretic therapy, furosemide, $40 \mathrm{mg}$ daily, and referred for an echocardiogram. This revealed a dilated left ventricle, with global hypokinesis and an ejection fraction estimated at $17 \%$. There was no significant valvular stenosis, or regional-wall motion abnormality, and mild-moderate mitral regurgitation was noted due to dilatation of the mitral annulus. An internal medicine physician reviewed the patient after the echocardiogram, and organised a CT coronary angiogram which showed no coronary disease. The patient was diagnosed with non-ischaemic, idiopathic, dilated cardiomyopathy and commenced on ramipril, $2.5 \mathrm{mg}$ daily. The patient was referred back to the family doctor with advice to continue titration of guideline-directed medical therapy.

\section{Uptake of Guideline Directed Medical Therapy Prescription of Medical Therapy}

Jennifer has been diagnosed with HF with reduced ejection fraction (HFrEF) due to dilated cardiomyopathy, and current guidelines recommend "triple-therapy" with ACE inhibitors or ARBs, beta-blockers and mineralocorticoid receptor antagonists (MRA)(6). The evidence itself is persuasive, with numbersneeded-to-treat as low as 8 for beta-blockers to prevent all-cause mortality at 5 years. ${ }^{25}$

Patients are routinely being commenced on these medications as shown in a number of international studies. In a prospective U.S. cohort of 15,177 patients with HFrEF, part of the IMPROVE HF study, $80 \%$ of patients enrolled were on ACE inhibitor/ARB therapy, $87 \%$ on beta-blockers and $35 \%$ on an MRA at baseline. ${ }^{26}$ This is comparable to the European Society of Cardiology (ESC) HF survey of 12,440 patients published in 2013, where prescription of ACE inhibitor/ARB, beta-blocker and MRA was 92\%, 93\% and $67 \%$ respectively. ${ }^{27}$ No comparable Canadian data have yet been published; however, unpublished sub-analyses of the QUALIFY registry ${ }^{28}$ show that $87 \%$ of patients were prescribed ACE inhibitor/ARB, 95\% beta-blocker and 50\% MRA.

Accordingly, our patient would usually be commenced on appropriate beta-blocker medication, such as bisoprolol, and an MRA such as spironolactone. The next issue is the titration of the medication to the doses studied in clinical trials and recommended in guidelines. 


\section{Medication Optimization to Target Doses}

The ESC survey showed that despite high rates of prescription of each drug class, patients were only on target doses of these medications $30 \%$ of the time, with two-thirds having documented reasons for not being on higher doses (including being in the process of dose optimization). ${ }^{27}$ U.S. data looking at patients on beta-blockers prior to admission for decompensated HF showed that those on beta-blockers were often at less than half the guideline recommended target dose. ${ }^{29}$

The guidelines for medication optimization are compelling, but the knowledge translation gap prevents them from impacting patient. Some have argued that while guidelines are now better at summarizing evidence behind recommendations, they do not always lend themselves to being easily implemented, lacking information to facilitate discussions with patients, summaries for different users of guidelines, whether in different professions or in different healthcare settings. ${ }^{30}$ A meta-analysis of 38 studies focussing on HF guideline intervention found that clinical pathways, multidisciplinary teams and multiple interventions were the most effective means to implement recommendations within guidelines. ${ }^{31}$ Here we briefly consider strategies for improving HF medication optimization.

\section{Multidisciplinary Clinics}

Nurse-led titration clinics have been suggested as means of improving prescription of guideline target doses of HF therapy. An Australian randomised trial showed faster titration of beta-blockers, with more patients reaching higher doses with nurse-led titration clinics compared to usual care. ${ }^{32}$ More recently, a Cochrane review looked at the role of nurse-led titration clinics, with 1,684 participants across 7 studies in their analysis. ${ }^{33}$ When hospitalization was considered (4 studies, 556 participants) there was a lower rate of hospital admission (relative risk $[\mathrm{RR}]=0.80,95 \% \mathrm{CI}$ : 0.72 to 0.88 , high-quality evidence) and fewer HF hospitalizations (RR $=0.51,95 \% \mathrm{CI}$ : 0.36 to 0.72 , moderate-quality evidence) in the nurse-titration clinic population compared to the usual-care group. Six studies (902 participants) examined all-cause mortality which was also lower in the nurse-led titration group ( $\mathrm{RR}=0.66,95 \% \mathrm{CI}$ : 0.48 to 0.92 , moderate-quality evidence) compared to usual care. Patients were also significantly more likely to be on target doses of medical therapy. ${ }^{33}$

A U.K.-based initiative of using a protocol-driven HF titration clinic staffed by nurses and specialist pharmacists showed a significant increase in patients on guideline directed medical therapy and at higher doses after 6 months, with the proportion of patients on "medium" or "high" doses of betablockers increasing from 18 to $57 \%$, and an increase from 55 to $86 \%$ for ACE inhibitors/ARB. There was also a reduction in the severity of HF in patients, with the proportion of severe HF (NYHA Class III and IV) declining from 40 to $23 \% .^{34} \mathrm{~A}$ pharmacist-based intervention in the ambulatory HF clinic of a U.S. hospital also showed a significant increase in the number of patients reaching target doses of ACE inhibitors/ARB (52.9\% versus $31 \%, p=0.007)$ and beta-blockers $(49 \%$ versus $24.7 \%$, $\mathrm{p}=0.012){ }^{35}$

\section{Outpatient Disease-Management Programmes}

Another opportunity to optimize medications occurs when patients are attending appointments for other reasons. An Australian study based saw the use of a disease-management program with a physician supported multi-disciplinary team, including specialist nurses and clinical pharmacists, educate patients on HF and optimize their medication as they attended exercise rehabilitation classes. ${ }^{36}$ The program included $216 \mathrm{HFrEF}$ patients and was associated with a significant increase in the proportion of patients on optimal ACE-inhibitor/ARB doses from 38\% at enrolment to $52 \%$ at 6 months $(\mathrm{p}=0.001)$ and on optimal beta blocker dosage from 23 to $49 \%(\mathrm{p}<0.001)$.

The same authors developed an iterative structured medication titration plan that could be used to target medication optimization after discharge from hospital prior to HF exacerbation. Patients could choose community-based nurses or their own primary care physician (if they agreed) to supervise titration of medications, with a single point of support from the HF disease management staff based in secondary care if needed. After two rounds of implementation, there was a significant increase in the number of patients on target doses of ACE inhibitors and beta-blockers after six months in the program. ${ }^{37}$

\section{Financial Incentives}

A large review has demonstrated that financial incentives to providers can improve the delivery of care in chronic conditions. Financial incentives showed an improvement in referral and also in optimizing the processes of care. ${ }^{38}$ No evidence currently exists on the effect of financial incentives on direct patient outcomes. Evidence from a systematic review of statin prescription amongst family doctors suggests that patients can become sceptical of the motives behind medication prescription if there is a financial incentive to do so. ${ }^{39}$ A U.S. study demonstrated that providing financial incentives to both patients and physicians significantly improved adherence to statin therapy and reduced LDL cholesterol levels, when compared to incentives to either physician or patient alone, or neither. ${ }^{40}$ While these have never been studied HF patients, it is an important consideration that could potentially assist with implanting guideline medical therapy. 


\section{Computerised Decision Support Systems}

Computerised clinical decision support systems can assist in the prescription of medicines in a safe and effective manner, ensuring that pre-requisites are met and that changing a medicine dose is appropriate. Research suggests that such support systems can improve process of care, but are rarely effective in improving patient outcomes. ${ }^{41}$ Without this evidence of benefit, they are not yet routinely available for use in HF management.

\section{What Does Optimal Treatment Look Like?}

One of the unanswered questions in HF management relates to what individually optimized HF medical management should look like. Given that the various trials have layered one therapy on another, first with ACE-inhibitors, then beta-blockers before MRA use, additional therapies are often added on top of these treatments. The landmark ICD trials were conducted in an era when MRAs were not routine treatment for HFrEF, and CRT was not widely used. The 2005 SCD-HeFT trial recruited 2,521 patients (a mixture of ischaemic and non-ischaemic cardiomyopathy) who were randomised to either placebo, amiodarone or ICD implantation, demonstrated a significant reduction in mortality with an ICD compared to placebo. ${ }^{42}$ When these trials were repeated in the era of CRT and MRA use, the investigators of the 2016 DANISH study found no reduction in all-cause mortality between groups randomised to ICD therapy when compared to no ICD implant. ${ }^{43}$ Similar to the earlier DEFINITE trial, there was a significant reduction in sudden cardiac death alone and not all-cause mortality. ${ }^{44}$

In an era when guideline directed medical therapy also includes neprilysin inhibitors, $\mathrm{I}_{\mathrm{f}}$ channel blockers, sodiumglucose transport protein 2 (SGLT2) inhibitors and a number of different device therapies, it can be challenging to navigate which drug should be added at which time, and whether one drug should be titrated upwards over another.

This is further complicated by the different patient phenotypes in real-world clinical practice compared to those enrolled clinical trials, who are predominantly young males with few additional co-morbidities such as renal dysfunction, hypotension and diabetes which may limit use of medical treatments. A review of the Euro Heart Survey in 2005 demonstrated that only 11\% of patients in this "real-world" registry would be eligible for the original ACE inhibitor, beta-blocker and MRA trials in HFrEF. ${ }^{45}$ More recently an analysis of a European ambulatory clinic showed only $42 \%$ of their patients would be eligible for entry into the PARADIGM-HF study, which investigated the efficacy of sacubitril/valsartan in HFrEF patients, based on inclusion criteria and contraindications. ${ }^{46}$ This poses unique challenges in knowledge translation to health care providers who may have limited experience in using these drugs and understanding who may be the most likely to benefit or be harmed by these medical interventions.

\section{Clinical Vignette (Part 3)}

Jennifer has been stabilised on daily doses of ramipril 10mg, bisoprolol $7.5 \mathrm{mg}$ and spironolactone $50 \mathrm{mg}$. She was unable to tolerate higher doses of the beta-blocker due to bradycardia. She remains symptomatic with NYHA Class II symptoms. Her ECG shows a narrow QRS complex, and after review in the regional heart function centre, she declined the offer of ICD implantation for primary prevention of sudden cardiac death. Repeat echocardiography shows severely impaired left ventricular function (ejection fraction 29\%). She is commenced on sacubitril/valsartan as an alternative to ramipril. During a follow-up clinic visit, she asked about any other therapies that might improve symptoms.

\section{Delays in Applying Novel Therapies}

A large number of treatments have been developed for the management of HFrEF, but there is always a lag between the emergence of evidence and the uptake of treatments in routine clinical practice. For example, in Ontario, there was a delay of 5 years in getting eplerenone funded by the Ontario Drug Benefits program after the EMPHASIS trial had shown efficacy of this drug in NYHA Class II HFrEF patients. ${ }^{47,48}$ There may be additional delays in the provincial approval for funding once Health Canada has approved a drug, leaving a gap where only those with private insurance or sufficient wealth to self-fund can access these life-saving therapies. ${ }^{49}$

Despite the pivotal CHAMPION trial being published in 2011, demonstrating a $37 \%$ reduction in HF-related hospitalisation ( $\mathrm{HR}=0 \cdot 63,95 \% \mathrm{CI}: 0 \cdot 52-0 \cdot 77)$ in patients with NYHA class III symptoms, regardless of ejection fraction, the device remains unfunded and can only be implanted through research trials or through charitable donations. It remains the only proven strategy in managing HF patients with preserved ejection fraction..$^{50}$

A possible solution to expedite new drug approvals might be a way to "fast-track" medications that have significant improvements in survival. In the U.K., the Medicines and Healthcare Products Regulatory Agency has an early access to medicines scheme which allows expedient access to pharmacologic therapies for life threatening or seriously debilitating conditions. ${ }^{51}$ Sacubitril/ valsartan was available for HFrEF patients within 9 months of publication of the PARADIGM-HF trial through this scheme, the first non-cancer medicine given this designation. ${ }^{52,53}$

\section{Future Directions}

A number of exciting propositions are on the horizon for improving knowledge translation in HF. While many countries use 
audit and quality improvement to judge how well guidelines are being implemented, there is currently no Canada-wide means to assess adherence to recommendations. ${ }^{54}$ Information is variably collected at a provincial level, but often the data sets are different between provinces precluding a comparison between healthcare providers across Canada. ${ }^{49,55}$ The U.K. National Heart Failure Audit was first established in 2007 and is used to assess all HF hospitalizations and whether they meet published clinical standards. ${ }^{56}$ The use of a nation-wide reporting tool for individual provider-level data has seen improvement in guideline implementation by demonstrating how clinics are performing compared to other providers. This needs to be an area of priority for HF policy makers to ensure best practice is followed in all parts of the country.

Several technological improvements are gaining momentum, and remote monitoring is a fundamental part of global HF care. ${ }^{57}$ Where some have tried medication optimization through telephone follow-up, the use of technology to monitor patients using smartphones lends itself well to being able to have a therapeutic dialog and alter HF medications in ambulatory patients without the need for in-person evaluation. ${ }^{58}$ The Medly programme is a remote monitoring system that uses algorithmic decision support; it has over 300 patients enrolled and is administered by a single nurse practitioner. ${ }^{59}$ A new, randomised trial will use the same remote monitoring technology to titrate medications remotely, comparing time to complete titration, maximal medicine dose achieved and number of clinic visits against usual in-office care. This could represent a scalable, automated, computer-assisted strategy of optimisation of HF medicines which may improve adherence to guidelines by circumventing some of the challenges of knowledge translation.

\section{Conclusions}

There are many delays in translating scientific discovery into elements that can be delivered as part of a HF management program. A large effort is required to communicate novel ideas to care providers dealing with HF. While patients currently resist increases in medication, HF specialists need to educate and empower patients to be more involved in their own management, and this is likely to require a change in mindset, where patients have better education around the risks of suboptimal medical management. Finally, from a nationwide perspective, the ability to monitor performance through a national audit should drive up quality of care and presumably inspire earlier approval and funding of proven HF medications and technologies.

\section{References}

1. Brahmbhatt DH, Cowie MR. Heart failure: classification and pathophysiology. Medicine (United Kingdom). 2018;46:587-93. doi: 10.1016/j.mpmed.2018.07.004
2. Cleland JG, Daubert JC, Erdmann E, Freemantle N, Gras D, Kappenberger $\mathrm{L}$, et al. The effect of cardiac resynchronization on morbidity and mortality in heart failure. N Engl J Med. 2005;352(15):1539-49. Epub 2005/03/09. doi: 10.1056/NEJMoa050496. PubMed PMID: 15753115.

3. Tang AS, Wells GA, Talajic M, Arnold MO, Sheldon R, Connolly S, et al. Cardiac-resynchronization therapy for mild-to-moderate heart failure. N Engl J Med. 2010;363(25):2385-95. Epub 2010/11/16. doi: 10.1056/ NEJMoa1009540. PubMed PMID: 21073365.

4. Moss AJ, Zareba W, Hall WJ, Klein H, Wilber DJ, Cannom DS, et al. Prophylactic implantation of a defibrillator in patients with myocardial infarction and reduced ejection fraction. N Engl J Med. 2002;346(12):877-83. Epub 2002/03/22. doi: 10.1056/NEJMoa013474. PubMed PMID: 11907286.

5. Team CCDS. Heart Disease in Canada. Public Health Agency of Canada, 2018 May 2018. Report No.

6. Ezekowitz JA, O’Meara E, McDonald MA, Abrams H, Chan M, Ducharme A, et al. 2017 Comprehensive Update of the Canadian Cardiovascular Society Guidelines for the Management of Heart Failure. Can J Cardiol. 2017;33(11):1342-433. Epub 2017/11/08. doi: 10.1016/j.cjca.2017.08.022. PubMed PMID: 29111106.

7. Services AH. Laboratory Report. 2012 February 2012. Report No.

8. Sepehrvand N, Bakal JA, Lin M, McAlister F, Wesenberg JC, Ezekowitz JA. Factors Associated With Natriuretic Peptide Testing in Patients Presenting to Emergency Departments With Suspected Heart Failure. Can J Cardiol. 2016;32(8):986 e1-8. Epub 2016/04/12. doi: 10.1016/j.cjca.2015.11.019. PubMed PMID: 27062232.

9. [cited 2019 22/12/2019]. Available from: https://choosingwiselycanada.org/.

10. Mathias JS, Baker DW. Developing quality measures to address overuse. JAMA. 2013;309(18):1897-8. Epub 2013/05/09. doi: 10.1001/jama.2013.3588. PubMed PMID: 23652520.

11. Roshanov PS, You JJ, Dhaliwal J, Koff D, Mackay JA, Weise-Kelly L, et al. Can computerized clinical decision support systems improve practitioners' diagnostic test ordering behavior? A decision-maker-researcher partnership systematic review. Implement Sci. 2011;6:88. Epub 2011/08/10. doi: 10.1186/1748-5908-6-88. PubMed PMID: 21824382; PubMed Central PMCID: PMCPMC3174115.

12. Rotter T, Kinsman L, James E, Machotta A, Gothe H, Willis J, et al. Clinical pathways: effects on professional practice, patient outcomes, length of stay and hospital costs. Cochrane Database Syst Rev. 2010(3):CD006632. Epub 2010/03/20. doi: 10.1002/14651858.CD006632.pub2. PubMed PMID: 20238347.

13. Lee DS, Tu JV, Juurlink DN, Alter DA, Ko DT, Austin PC, et al. Risktreatment mismatch in the pharmacotherapy of heart failure. JAMA. 2005;294(10):1240-7. Epub 2005/09/15. doi: 10.1001/jama.294.10.1240. PubMed PMID: 16160132.

14. Peterson PN, Rumsfeld JS, Liang L, Hernandez AF, Peterson ED, Fonarow GC, et al. Treatment and risk in heart failure: gaps in evidence or quality? Circ Cardiovasc Qual Outcomes. 2010;3(3):309-15. Epub 2010/04/15. doi: 10.1161/CIRCOUTCOMES.109.879478. PubMed PMID: 20388872.

15. Ambardekar AV, Thibodeau JT, DeVore AD, Kittleson MM, Forde-McLean RC, Palardy M, et al. Discordant Perceptions of Prognosis and Treatment Options Between Physicians and Patients With Advanced Heart Failure. JACC Heart Fail. 2017;5(9):663-71. Epub 2017/08/22. doi: 10.1016/j. jchf.2017.04.009. PubMed PMID: 28822745; PubMed Central PMCID: PMCPMC5609812.

16. Canepa M, Fonseca C, Chioncel O, Laroche C, Crespo-Leiro MG, Coats AJS, et al. Performance of Prognostic Risk Scores in Chronic Heart Failure Patients Enrolled in the European Society of Cardiology Heart Failure LongTerm Registry. JACC Heart Fail. 2018;6(6):452-62. Epub 2018/06/02. doi: 10.1016/j.jchf.2018.02.001. PubMed PMID: 29852929.

17. Howlett JG. Should we perform a heart failure risk score? Circ Heart Fail. 2013;6(1):4-5. Epub 2013/01/17. doi: 10.1161/ CIRCHEARTFAILURE.112.973172. PubMed PMID: 23322877.

18. Harkness K, Heckman G, McKelvie R, Forsey A, Kingsbury K. Outpatient Management of Patients with Heart Failure. Austin J Clin Cardiolog. 2014;1(4):1028. 
19. Smeets M, Van Roy S, Aertgeerts B, Vermandere M, Vaes B. Improving care for heart failure patients in primary care, GPs' perceptions: a qualitative evidence synthesis. BMJ Open. 2016;6(11):e013459. Epub 2016/12/03. doi: 10.1136/bmjopen-2016-013459. PubMed PMID: 27903565; PubMed Central PMCID: PMCPMC5168518.

20. Flodgren G, Parmelli E, Doumit G, Gattellari M, O’Brien MA, Grimshaw J, et al. Local opinion leaders: effects on professional practice and health care outcomes. Cochrane Database Syst Rev. 2011(8):CD000125. Epub 2011/08/13. doi: 10.1002/14651858.CD000125.pub4. PubMed PMID: 21833939; PubMed Central PMCID: PMCPMC4172331.

21. Forsetlund L, Bjorndal A, Rashidian A, Jamtvedt G, O’Brien MA, Wolf $\mathrm{F}$, et al. Continuing education meetings and workshops: effects on professional practice and health care outcomes. Cochrane Database Syst Rev. 2009(2):CD003030. Epub 2009/04/17. doi: 10.1002/14651858.CD003030. pub2. PubMed PMID: 19370580.

22. Peters-Klimm F, Natanzon I, Muller-Tasch T, Ludt S, Nikendei C, Lossnitzer $\mathrm{N}$, et al. Barriers to guideline implementation and educational needs of general practitioners regarding heart failure: a qualitative study. GMS Z Med Ausbild. 2012;29(3):Doc46. Epub 2012/06/28. doi: 10.3205/zma000816. PubMed PMID: 22737201; PubMed Central PMCID: PMCPMC3374142.

23. Hayes SM, Peloquin S, Howlett JG, Harkness K, Giannetti N, Rancourt C, et al. A qualitative study of the current state of heart failure community care in Canada: what can we learn for the future? BMC Health Serv Res. 2015;15:290. Epub 2015/07/29. doi: 10.1186/s12913-015-0955-4. PubMed PMID: 26216103; PubMed Central PMCID: PMCPMC4515922.

24. Wyer P, Stojanovic Z, Shaffer JA, Placencia M, Klink K, Fosina MJ, et al. Combining training in knowledge translation with quality improvement reduced 30-day heart failure readmissions in a community hospital: a case study. J Eval Clin Pract. 2016;22(2):171-9. Epub 2015/09/25. doi: 10.1111/ jep.12450. PubMed PMID: 26400781.

25. Srivastava PK, Claggett BL, Solomon SD, McMurray JJV, Packer M, Zile MR, et al. Estimated 5-Year Number Needed to Treat to Prevent Cardiovascular Death or Heart Failure Hospitalization With Angiotensin Receptor-Neprilysin Inhibition vs Standard Therapy for Patients With Heart Failure With Reduced Ejection Fraction: An Analysis of Data From the PARADIGM-HF Trial. JAMA Cardiol. 2018;3(12):1226-31. Epub 2018/11/30. doi: 10.1001/jamacardio.2018.3957. PubMed PMID: 30484837; PubMed Central PMCID: PMCPMC6583093.

26. Fonarow GC, Albert NM, Curtis AB, Gheorghiade M, Heywood JT, Liu Y, et al. Associations between outpatient heart failure process-of-care measures and mortality. Circulation. 2011;123(15):1601-10. Epub 2011/04/06. doi: 10.1161/CIRCULATIONAHA.110.989632. PubMed PMID: 21464053.

27. Maggioni AP, Anker SD, Dahlstrom U, Filippatos G, Ponikowski P, Zannad F, et al. Are hospitalized or ambulatory patients with heart failure treated in accordance with European Society of Cardiology guidelines? Evidence from 12,440 patients of the ESC Heart Failure Long-Term Registry. Eur J Heart Fail. 2013;15(10):1173-84. Epub 2013/08/28. doi: 10.1093/eurjhf/hft134. PubMed PMID: 23978433.

28. Komajda M, Cowie MR, Tavazzi L, Ponikowski P, Anker SD, Filippatos GS, et al. Physicians' guideline adherence is associated with better prognosis in outpatients with heart failure with reduced ejection fraction: the QUALIFY international registry. Eur J Heart Fail. 2017;19(11):1414-23. Epub 2017/05/04. doi: 10.1002/ejhf.887. PubMed PMID: 28463464.

29. Fonarow GC, Abraham WT, Albert NM, Stough WG, Gheorghiade M, Greenberg BH, et al. Dosing of beta-blocker therapy before, during, and after hospitalization for heart failure (from Organized Program to Initiate Lifesaving Treatment in Hospitalized Patients with Heart Failure). Am J Cardiol. 2008;102(11):1524-9. Epub 2008/11/26. doi: 10.1016/j. amjcard.2008.07.045. PubMed PMID: 19026308.

30. Gagliardi AR, Brouwers MC, Palda VA, Lemieux-Charles L, Grimshaw JM. How can we improve guideline use? A conceptual framework of implementability. Implement Sci. 2011;6:26. Epub 2011/03/24. doi: 10.1186/1748-5908-6-26. PubMed PMID: 21426574; PubMed Central PMCID: PMCPMC3072935.
31. Shanbhag D, Graham ID, Harlos K, Haynes RB, Gabizon I, Connolly SJ, et al. Effectiveness of implementation interventions in improving physician adherence to guideline recommendations in heart failure: a systematic review. BMJ Open. 2018;8(3):e017765. Epub 2018/03/08. doi: 10.1136/ bmjopen-2017-017765. PubMed PMID: 29511005; PubMed Central PMCID: PMCPMC5855256.

32. Driscoll A, Srivastava P, Toia D, Gibcus J, Hare DL. A nurse-led up-titration clinic improves chronic heart failure optimization of beta-adrenergic receptor blocking therapy--a randomized controlled trial. BMC Res Notes. 2014;7:668. Epub 2014/09/25. doi: 10.1186/1756-0500-7-668. PubMed PMID: 25248944; PubMed Central PMCID: PMCPMC4182807.

33. Driscoll A, Currey J, Tonkin A, Krum H. Nurse-led titration of angiotensin converting enzyme inhibitors, beta-adrenergic blocking agents, and angiotensin receptor blockers for people with heart failure with reduced ejection fraction. Cochrane Database Syst Rev. 2015(12):CD009889. Epub 2015/12/23. doi: 10.1002/14651858.CD009889.pub2. PubMed PMID: 26689943.

34. Jain A, Mills P, Nunn LM, Butler J, Luddington L, Ross V, et al. Success of a multidisciplinary heart failure clinic for initiation and up-titration of key therapeutic agents. Eur J Heart Fail. 2005;7(3):405-10. Epub 2005/02/19. doi: 10.1016/j.ejheart.2004.09.009. PubMed PMID: 15718181.

35. Martinez AS, Saef J, Paszczuk A, Bhatt-Chugani H. Implementation of a pharmacist-managed heart failure medication titration clinic. Am J Health Syst Pharm. 2013;70(12):1070-6. Epub 2013/05/31. doi: 10.2146/ajhp120267. PubMed PMID: 23719886.

36. Carroll R, Mudge A, Suna J, Denaro C, Atherton J. Prescribing and uptitration in recently hospitalized heart failure patients attending a disease management program. Int J Cardiol. 2016;216:121-7. Epub 2016/05/07. doi: 10.1016/j.ijcard.2016.04.084. PubMed PMID: 27153136.

37. Hickey A, Suna J, Marquart L, Denaro C, Javorsky G, Munns A, et al. Improving medication titration in heart failure by embedding a structured medication titration plan. Int J Cardiol. 2016;224:99-106. Epub 2016/10/25. doi: 10.1016/j.ijcard.2016.09.001. PubMed PMID: 27643473.

38. Flodgren G, Eccles MP, Shepperd S, Scott A, Parmelli E, Beyer FR. An overview of reviews evaluating the effectiveness of financial incentives in changing healthcare professional behaviours and patient outcomes. Cochrane Database Syst Rev. 2011(7):CD009255. Epub 2011/07/08. doi: 10.1002/14651858.CD009255. PubMed PMID: 21735443; PubMed Central PMCID: PMCPMC4204491.

39. Ju A, Hanson CS, Banks E, Korda R, Craig JC, Usherwood T, et al. Patient beliefs and attitudes to taking statins: systematic review of qualitative studies. Br J Gen Pract. 2018;68(671):e408-e19. Epub 2018/05/23. doi: 10.3399/ bjgp18X696365. PubMed PMID: 29784867; PubMed Central PMCID: PMCPMC6002012.

40. Asch DA, Troxel AB, Stewart WF, Sequist TD, Jones JB, Hirsch AG, et al. Effect of Financial Incentives to Physicians, Patients, or Both on Lipid Levels: A Randomized Clinical Trial. JAMA. 2015;314(18):1926-35. Epub 2015/11/10. doi: 10.1001/jama.2015.14850. PubMed PMID: 26547464; PubMed Central PMCID: PMCPMC5509443.

41. Hemens BJ, Holbrook A, Tonkin M, Mackay JA, Weise-Kelly L, Navarro T, et al. Computerized clinical decision support systems for drug prescribing and management: a decision-maker-researcher partnership systematic review. Implement Sci. 2011;6:89. Epub 2011/08/10. doi: 10.1186/1748-5908-6-89. PubMed PMID: 21824383; PubMed Central PMCID: PMCPMC3179735.

42. Bardy GH, Lee KL, Mark DB, Poole JE, Packer DL, Boineau R, et al. Amiodarone or an implantable cardioverter-defibrillator for congestive heart failure. N Engl J Med. 2005;352(3):225-37. Epub 2005/01/22. doi: 10.1056/ NEJMoa043399. PubMed PMID: 15659722.

43. Kober L, Thune JJ, Nielsen JC, Haarbo J, Videbaek L, Korup E, et al. Defibrillator Implantation in Patients with Nonischemic Systolic Heart Failure. N Engl J Med. 2016;375(13):1221-30. Epub 2016/08/30. doi: 10.1056/ NEJMoa1608029. PubMed PMID: 27571011.

44. Kadish A, Dyer A, Daubert JP, Quigg R, Estes NA, Anderson KP, et al. Prophylactic defibrillator implantation in patients with nonischemic dilated 
cardiomyopathy. N Engl J Med. 2004;350(21):2151-8. Epub 2004/05/21. doi: 10.1056/NEJMoa033088. PubMed PMID: 15152060.

45. Lenzen MJ, Boersma E, Reimer WJ, Balk AH, Komajda M, Swedberg K, et al. Under-utilization of evidence-based drug treatment in patients with heart failure is only partially explained by dissimilarity to patients enrolled in landmark trials: a report from the Euro Heart Survey on Heart Failure. Eur Heart J. 2005;26(24):2706-13. Epub 2005/09/27. doi: 10.1093/eurheartj/ ehi499. PubMed PMID: 16183692.

46. Rodrigues G, Tralhao A, Aguiar C, Freitas P, Ventosa A, Mendes M. Is the PARADIGM-HF cohort representative of the real-world heart failure patient population? Rev Port Cardiol. 2018;37(6):491-6. Epub 2018/05/22. doi: 10.1016/j.repc.2017.09.023. PubMed PMID: 29779951.

47. Programs OPD. Eplerenone for heart failure. Drugs CtE; 2016.

48. Zannad F, McMurray JJ, Krum H, van Veldhuisen DJ, Swedberg K, Shi H, et al. Eplerenone in patients with systolic heart failure and mild symptoms. N Engl J Med. 2011;364(1):11-21. Epub 2010/11/16. doi: 10.1056/ NEJMoa1009492. PubMed PMID: 21073363.

49. Virani SA, Bains M, Code J, Ducharme A, Harkness K, Howlett JG, et al. The Need for Heart Failure Advocacy in Canada. Can J Cardiol. 2017;33(11):1450-4. Epub 2017/11/08. doi: 10.1016/j.cjca.2017.08.024. PubMed PMID: 29111108.

50. Abraham WT, Adamson PB, Bourge RC, Aaron MF, Costanzo MR, Stevenson LW, et al. Wireless pulmonary artery haemodynamic monitoring in chronic heart failure: a randomised controlled trial. The Lancet. 2011;377(9766):65866. doi: 10.1016/s0140-6736(11)60101-3.
51. The Early Access To Medicine Scheme [22/12/2019]. Available from: https:// www.gov.uk/guidance/apply-for-the-early-access-to-medicines-scheme-eams.

52. McMurray JJ, Packer M, Desai AS, Gong J, Lefkowitz MP, Rizkala AR, et al. Angiotensin-neprilysin inhibition versus enalapril in heart failure. N Engl J Med. 2014;371(11):993-1004. Epub 2014/09/02. doi: 10.1056/ NEJMoa1409077. PubMed PMID: 25176015.

53. [22/12/2019]. Available from: https://pumpingmarvellous.org/ lcz696-sacubitril-valsartan-available-to-nhs-through-eams/.

54. Jamtvedt G, Young JM, Kristoffersen DT, O’Brien MA, Oxman AD. Does telling people what they have been doing change what they do? A systematic review of the effects of audit and feedback. Qual Saf Health Care. 2006;15(6):433-6. Epub 2006/12/05. doi: 10.1136/qshc.2006.018549. PubMed PMID: 17142594; PubMed Central PMCID: PMCPMC2464905.

55. Heart Failure: Care in the Community for Adults. In: Standards CO-Q, editor. 2019.

56. NICOR. UK National Heart Failure Audit 2016/17 2019.

57. Brahmbhatt DH, Cowie MR. Remote Management of Heart Failure: An Overview of Telemonitoring Technologies. Card Fail Rev. 2019;5(2):86-92. Epub 2019/06/11. doi: 10.15420/cfr.2019.5.3. PubMed PMID: 31179018; PubMed Central PMCID: PMCPMC6545972.

58. Moyer-Knox D, Mueller TM, Vuckovic K, Mischke L, Williams RE. Remote titration of carvedilol for heart failure patients by advanced practice nurses. Journal of Cardiac Failure. 2004;10(3):219-24. doi: 10.1016/j. cardfail.2003.09.009. PubMed PMID: 15190531.

59. Medly [22/12/2019]. Available from: https://medly.ca/.

\section{Continued from page 26}

32. Machaj F, Dembowska E, Rosik J, et al. New therapies for the treatment of heart failure: a summary of recent accomplishments. Therapeut Clinical Risk Manage 2019;15:147.

33. Tsai EJ and Kass DA. Cyclic GMP signaling in cardiovascular pathophysiology and therapeutics. Pharmacol Therapeutics 2009;122:216-38.

34. Ontkean M, Gay R, and Greenberg B. Diminished endothelium-derived relaxing factor activity in an experimental model of chronic heart failure. Circulat Res 1991;69:1088-1096.

35. Shah SJ, Kitzman DW, Borlaug BA, et al. Phenotype-specific treatment of heart failure with preserved ejection fraction: a multiorgan roadmap. Circulation 2016;134:73-90.

36. Marti CN, Gheorghiade M, Kalogeropoulos AP, et al. Endothelial dysfunction, arterial stiffness, and heart failure. J Am Coll Cardiol 2012;60:1455-69.
37. Ghofrani H-A, Humbert M, Langleben D, et al. Riociguat: mode of action and clinical development in pulmonary hypertension. Chest 2017;151:468-80.

38. Ghofrani H-A, D'Armini AM, Grimminger F, et al. Riociguat for the treatment of chronic thromboembolic pulmonary hypertension. N Engl J Med 2013;369:319-29.

39. Armstrong PW, Roessig L, Patel MJ, et al. A multicenter, randomized, double-blind, placebo-controlled trial of the efficacy and safety of the oral soluble guanylate cyclase stimulator: The VICTORIA Trial. JACC: Heart Failure 2018;6:96-104. 